${ }^{\text {I }}$ Universidade Federal do Rio de Janeiro (UFRJ),

Programa de Pós-Graduação em Antropologia Social,

Museu Nacional, Rio de Janeiro, RJ, Brasil

bmuniz@gmail.com

Bruno Barboza Muniz'

\title{
QUEM PRECISA DE CULTURA? \\ O CAPITAL EXISTENCIAL DO FUNK E A CONVENIÊNCIA DA CULTURA
}

No final de 2015 os "arrastões" nas praias cariocas voltaram a ser notícia. Para alguns, tal situação teria base estrutural e seria fruto de uma sociedade desigual e racista. Para outros, tratar-se-ia de um problema de polícia e ordem pública.

Acredito que devemos, sim, considerar as condições estruturais para melhor entendermos o que acontece no mundo e em nossa cidade. Contudo, existe sempre o risco iminente de explicarmos o social pelo social, como alertou Latour (2005). Muitas vezes o caminho que leva condições estruturais a gerarem ações não é considerado a contento. O objetivo deste texto é explorar, ainda que de maneira incompleta, como a estrutura social se relaciona com a prática cultural trazendo para o centro do debate um componente por vezes pouco lembrado: o afeto.

Não estou interessado em pensar nas causas do arrastão, mas no engajamento com a música funk. Neste caso, provavelmente o leitor deve estar se perguntando por que então comecei este artigo mencionando os "arrastões".

As primeiras aparições de discussões sobre "arrastões" na imprensa nos anos I99o estiveram relacionadas ao funk. Manchetes como "Movimento funk leva desesperança" e outras semelhantes ajudaram a criminalizar o funk, descrevendo como jovens "funkeiros" causavam pânico nas praias da Zona Sul, uma das áreas mais ricas e turísticas do Rio de Janeiro (Yúdice, 2003; Herschmann, 2005; Lopes, 20II; Facina, 20I4). Apesar da narrativa jor- 
nalística se tornar mais ambígua a partir do final dos anos I990, conforme a classe média começa a aderir ao estilo, o funk continua a figurar como um elemento associado a condutas criminosas (Lopes, 20II). Contudo, para ser assimilado pela imprensa, uma divisão é introduzida e o funk passa a ser distinguido entre o "funk do bem" e o "funk do mal" (Lopes, 20II: 50).

Estruturas sociais se articulam com um sentimento afetivo de reconhecimento ou de falta de reconhecimento por parte da juventude carioca. As políticas públicas implementadas pelo Estado do Rio de Janeiro-neste caso me refiro principalmente às Unidades de Polícia Pacificadora (UPPs) - não só deixaram de lado o jovem como reprimiram locais e eventos onde o jovem morador de favela pode se expressar e sociabilizar, como os bailes funk (Facina, 20I4; Facina \& Passos, 20I5). O projeto da UPP consiste na ocupação permanente de favelas do Rio de Janeiro por policiais. Nos últimos anos, críticas relativas aos abusos cometidos por policiais locados nestas Unidades se tornaram cada vez mais frequentes, principalmente depois do caso Amarildo, pedreiro morto e torturado pela polícia (Ganem Misse, 2014).

Utilizo aqui materiais da minha pesquisa de doutorado coletados entre $20 I$ I e 20I4, quando realizei observação participante no Rio de Janeiro em eventos políticos e culturais ligados ao funk, bem como 24 entrevistas semiestruturadas. Dentre o material coletado, destacarei eventos específicos e entrevistas com jovens dançarinos de passinho, ainda que eu mencione também entrevistas com MCs, DJs e produtores.

As entrevistas com dançarinos são especialmente ilustrativas da importância de se estudar o que Nettleton (2013) denominou capital existencial. Por se tratar de uma atividade praticada por jovens, o estudo do passinho tem o potencial de esclarecer como repertórios utilizados hoje por comunidades afetivas de dançarinos podem ter um impacto no futuro. Defendo, ao longo deste texto, a importância de se considerar não apenas capitais que geram valor a partir de apropriações individuais, mas também uma forma de capital capaz de gerar valor partindo de formações coletivas, o capital existencial.

O habitante de favela, incluindo o jovem, ainda luta para ser reconhecido como "gente" (Perlman, 2010), como alguém que existe. Não apenas um espectro que vez ou outra ronda áreas ricas da cidade provocando desespero. Consequentemente, a produção cultural nestas áreas encontra dificuldades para se afirmar e adquirir legitimidade. Aqueles envolvidos com o funk frequentemente se veem obrigados a defender a cultura que produzem recorrendo à sua conveniência. Inspirando-me em Yúdice (2003), questiono quais são as conseqüências de se pensar o funk hoje pela perspectiva da conveniência da cultura.

Nas próximas duas seções me empenho em explicitar as bases teóricas da argumentação que elaboro. Primeiro, discuto as noções de capital existen- 
cial, reconhecimento e afeto. Em seguida, desenvolvo a relação entre os conceitos de afeto e differance, ressaltando a importância desta relação para a compreensão do conceito de capital existencial e da demanda por reconhecimento de artistas que produzem funk. Passo então a descrever na seção seguinte um estilo de dança marcado pela mistura criativa de diversas influências chamado passinho. Nesta mesma seção, discuto um encontro relevante para o meu argumento, narrado a mim por dois dançarinos. Este encontro exemplifica como os dançarinos de passinho assumem um papel de liderança e reconhecimento entre seus pares.

Em seguida, passo a considerar a relação entre aqueles que dançam passinho e "outros", como produtores, jornalistas e alguns indivíduos escolhidos para julgar o passinho em concursos de dança, discutindo também como o passinho se relaciona com a formação de comunidades afetivas, as quais são relevantes para a geração de capital existencial. Por fim, concluo que a própria necessidade de se defender o funk como algo útil já evidencia preconceitos existentes contra o estilo.

\section{CAPITAL EXISTENCIAL, RECONHECIMENTO E AFETO}

Introduzo nesta seção três conceitos: capital existencial, reconhecimento e afeto. Parto destes conceitos para propor uma perspectiva crítica ao pensamento de Bourdieu sem descartar suas contribuições. Esta perspectiva visa também resgatar elementos da sua teoria negligenciados por apropriações posteriores. Tais elementos, apresentados no livro Meditações pascalianas (Bourdieu, 200I), podem ser sintetizados na ideia de um modelo disposicional em que o afeto e o corpo ganham proeminência. Estas instâncias não foram ignoradas pelo pensador francês, mas a proliferação na literatura de termos como capital econômico, capital cultural e capital social indicam um viés economicista na apropriação de seu pensamento.

Por exemplo, a noção de habitus remete a disposições internalizadas corporalmente por indivíduos, tomando também a forma de expectativas que são confirmadas ou frustradas. Este processo, que também é parte de uma trajetória, gera um conhecimento prático e afetivo do mundo que permite a todos nós agirmos não no âmbito de uma racionalidade cartesiana, mas guiados por ações que apenas ganham sentido dentro de um determinado campo. Contudo, tal adequação entre ações estruturadas por um habitus e campos diversos (como o campo das artes) é marcada pelo que Bourdieu caracterizou como "encontros obscuros" (Bourdieu, 200I: I4I).

Esta obscuridade pode ser parcialmente esclarecida através do estudo do afeto, para o qual é válido introduzirmos o conceito de reconhecimento, cuja "dependência simbólica" é realçada e criticada por Bourdieu. Por sua vez, Watkins (20I0) propõe que, visto de uma perspectiva que privilegia a dimensão afetiva, o reconhecimento não necessariamente reforça a dialética mes- 
tre/escavo formulada por Hegel, mas pode contribuir para um sentimento de valorização do aluno (Watkins, 2010). Devemos lembrar, porém, que o oposto também pode acontecer, por exemplo, quando o aluno é destacado e marcado pelo professor devido ao seu baixo desempenho escolar.

No entanto, uma dificuldade específica aparece em diversas contribuições ao tema do afeto: a divisão entre afeto e sua representação ou entre afeto e linguagem (Massumi, I995). A relação entre afeto e sua estabilização na forma de linguagem, como emoções ou sentimentos, não é tão direta quanto se supõe. Prazer e felicidade não estão necessária e positivamente correlacionados, e as formas como vivenciamos corporalmente tais afetos são descritas por palavras de maneira contraditória (Massumi, I995).

As contradições do afeto foram inúmeras vezes narradas pela música brasileira. Vinicius de Moraes em parceria com Tom Jobim expôs nas letras de suas canções a efemeridade da felicidade. Em uma delas, Vinicius fala da importância da tristeza para se fazer um "samba com beleza". Cartola, em "A cor da esperança”, espera que a tristeza transforme-se em alegria, mas apenas "amanhã". Os exemplos são numerosos. Já no funk, uma canção chamada "Rap da felicidade", de Cidinho e Doca, que já pode ser considerado um clássico, diz: "eu só quero é ser feliz e andar tranquilamente na favela onde eu nasci”. A letra então passa a narrar a situação de injustiça social vivida pelos habitantes de favelas.

Emoção e afeto não são a mesma coisa. Falar de afeto no contexto do funk não significa afirmar que este traz felicidade ou prazer para os jovens de favela. Felicidade ou prazer são apenas traduções do afeto, que Massumi e outros (Clough, 2010; Skeggs, 2000) caracterizam como sendo autônomo. Dificilmente podemos enquadrar a noção de afeto dentro do binômio positivo/ negativo, nos permitindo uma análise livre dos maniqueísmos que costumam permear análises sobre a relação entre a favela e o restante da cidade.

Contudo, a percepção de que o afeto é autônomo e efêmero tende a dificultar o seu uso para a compreensão de formas estruturais de segregação. Assim sendo, precisamos de conceitos que nos ajudem a fixar, mesmo que provisoriamente, a afetividade. O estudo da noção de classe social pode se beneficiar imensamente de uma abordagem em que a demanda por reconhecimento é associada com afetos, mas não afetos efêmeros e desconectados da estrutura social. Neste contexto, a afetividade interage com julgamentos morais e valorativos sobre práticas sociais, culturais e artísticas (Sayer, 2005).

O conceito de capital existencial desenvolvido por Nettleton (2013) mostra-se fundamental, pois implica ganhos afetivos que podem ser analisados de um ponto de vista individual, mas que decorrem de uma atuação coletiva. Diferentes tipos de capital são discutidos como ganhos resultantes de práticas competitivas e lutas que estabelecem distinções entre posições sociais no interior de campos relativamente autônomos. Por sua vez, o valor 
do capital existencial decorre daquilo que as pessoas possuem em comum, como valores e práticas compartilhados (Nettleton, 2013).

\section{AFETO, DIFFERANCE E A MÚSICA FUNK}

A noção de différance (ou differance, como o neologismo foi traduzido para o inglês) proposta por Derrida (I968) serve para ilustrar as articulações possíveis entre agência, afeto e estrutura. O termo differance difere do termo difference através do sufixo -ance, existente tanto no francês quanto no inglês. O foco não é a ação, como na expressão to differ ou différer (algo como discordar), nem uma situação presente, expressa pela palavra different ou différant (diferente).

A diferença entre differance e difference (utilizarei aqui o inglês) foi enunciada verbalmente por Derrida durante uma palestra. De acordo com ele, sem referir-se explicitamente a esta diferença decorrente da mudança de uma letra, imperceptível somente através da fala, o público não entenderia sua palestra. Assim, a differance não reside na escrita ou na voz, tampouco na estrutura ou no som, ou mesmo em sua posterior assimilação pelo sentido da audição. O conceito de differance ilustra a incompletude e a efemeridade da relação entre signo e significado. De acordo com Derrida, essa relação nunca se esgota em si mesma, pois signos adicionais são necessários para estabelecer um significado, que é continuamente adiado.

Para exemplificar a relevância da noção de differance discutirei um estudo sobre a relação entre afeto e renda. Tal pesquisa argumenta que uma renda maior não necessariamente acompanha maiores índices de felicidade, mas a pobreza material, ao que tudo indica, pode gerar tristeza (Kushlev et al., 20I5). Os autores acertadamente apontam que felicidade e tristeza são "estados emocionais distintos" e não opostos em uma escala linear. No entanto, falham em reconhecer que, enquanto emoções (como a felicidade e a tristeza) são traduções do afeto, este é inerentemente relacional e corporificado.

Este entendimento do afeto justifica o nosso foco em dançarinos de passinho, uma vez que a discussão sobre o corpo apareceu de maneira pronunciada durante meu trabalho de campo. A sistematização de emoções e sentimentos para fins de análise social, como conduzida por Kushlev et al. (20I5), limita-se a enfocar a representação do afeto - isto é, a atenção está na forma como um estado afetivo é expresso. Ou seja, realça-se a inteligibilidade e não a afetividade e sua presença corpórea.

A noção de differance torna-se útil, pois permite um entendimento de que a afetividade, assim como a voz, marcada pela efemeridade, e a estrutura, caracterizada pela estabilidade, não são opostos, mas elaborações contingentes e interdependentes sobre a realidade. A produção de distinção social articula-se com a produção de um determinado tipo de diferença, uma diferença material e estrutural associada com a mobilização de capitais diversos e com a competitividade intra e inter campos. Pretendo argumentar que o 
capital existencial, por sua vez, refere-se à differance, noção segundo a qual, vale enfatizar, a alteridade e a semelhança não são opostos, mas produções coletivas marcadas por uma inevitável contingência.

Para entender a noção de capital existencial, o reconhecimento e a differance mostram-se mais significativos do que a distinção. Este foco permite uma compreensão da noção de agência, não mais pautada somente no indivíduo e sua posição, mas na ação coletiva e seus desdobramentos simbólicos, corporais e estruturais. Neste ponto, divirjo, ao menos em parte, da noção de capital existencial proposta por Nettleton (2013), já que, a meu ver, os ganhos derivados daquilo que se compartilha, como causas políticas ou práticas culturais e corporais, não são adequadamente compreendidos pela noção de identidade. Não pretendo aqui desenvolver uma longa crítica deste conceito, mas apenas indicar que ele pode servir para minimizar divergências internas a certos campos e para enfatizar um excessivo essencialismo em detrimento da afetividade e interseccionalidade, como discutido por Nash (20II) em relação ao feminismo negro.

Durante meu trabalho de campo e através da leitura de bibliografia pertinente ao funk, pude perceber diferentes formas de relação entre estrutura social e o engajamento afetivo com o funk. Este aparece como uma forma de escape afetivo dos problemas enfrentados por fãs, artistas e produtores, problemas que podem ser causados pelo racismo estrutural, segregação espacial ou falta de recursos materiais. O funk também oferece esperança e otimismo, ao introduzir uma realidade de abundância e prazer quase que ilimitado, como no caso do funk ostentação. Em outras situações, o funk e o ativismo político se aproximam, como no caso de funkeiras feministas ou dos ativistas da APAFUNK (Associação de Profissionais e Amigos do Funk), criada para defender os direitos dos funkeiros. ${ }^{2}$

Nos casos citados acima estamos realçando características instrumentais do funk quando apropriado para fins individuais - como, por exemplo, para lidar com problemas cotidianos ou obter renda -, ou coletivos, como na luta política. No entanto, o funk também se apresenta como uma cena onde comunidades afetivas são criadas. Neste caso, o capital existencial ganha preeminência em relação ao caráter instrumental do funk.

A ideia de capital existencial é crucial para a nossa compreensão do funk: a luta por legitimidade e contra preconceitos travada diariamente por aqueles envolvidos com esta prática musical suscita a necessidade constante de justificar a sua existência. Observei esta tendência durante entrevistas, nas quais o funk era constantemente citado como uma prática capaz de gerar renda, afastar as crianças e adolescentes do crime e das drogas e até ajudar no processo de alfabetização. Nas palavras de DJ Marlboro, por exemplo, um personagem extremamente envolvido na popularização do funk: 
A importância social do funk é muito grande, [...] o funk é a onda que mais funciona no Brasil a nível de cidadania, de resgate dos jovens do tráfico, da marginalidade, o que for. Não existe ONG no Brasil que tire tantos jovens da marginalidade quanto o funk.

É razoável assumirmos que práticas aceitas e legitimadas estão associadas com elevado capital existencial, uma vez que não requerem maiores explicações para a sua existência. Estilos como o samba (estigmatizado no passado), a MPB ou a música clássica não precisam gerar efeitos positivos e terem estes efeitos lembrados. Este não é o caso do funk. No entanto, ao analisarmos narrativas de dançarinos percebemos o quanto o fenômeno da dança é capaz de criar grupos - chamados pelos dançarinos de bondes ou até mesmo famílias - e laços afetivos, que muitas vezes não se conformam a diferenças de idade ou classe social. Dançarinos também provocam admiração e viram modelos para os mais novos.

Neste sentido, crianças, jovens e adultos se reúnem para escutar e dançar funk porque gostam, por causa do afeto que os une à música e uns aos outros. Num segundo momento, consequências diversas podem emergir dessas comunidades afetivas formadas através da música, mas é importante reconhecermos que essas possibilidades se explicam em parte devido ao afeto. Com o objetivo de exemplificar os argumentos acima, analiso a seguir um encontro específico entre Cebolinha e Baianinho, narrado para mim por ambos durante entrevistas.

\section{O ENCONTRO NO JACARÉ}

Todos os dançarinos a serem citados representam ídolos para os garotos mais jovens. Isto ocorre por algumas razões, entre elas a idade. Cebolinha, um dos participantes desta pesquisa, já tem 26 anos, ao passo que muitos daqueles começando na cena do passinho hoje são crianças. Experiência e visibilidade também contam muito: tanto Cebolinha como Baianinho já apareceram na grande mídia, em programas de televisão, revistas e jornais. Como consequência, eles passam a desempenhar um papel de liderança em suas comunidades.

Uma situação que demonstra este papel de liderança ocorreu durante a exibição do filme "Batalha do passinho", no Morro da Providência, em 2013. Em um determinado momento, antes das palestras programadas no evento, Cebolinha se retirou do local, arrastando com ele uma multidão de meninos. Emílio3, diretor do documentário, teve que ligar para Cebolinha e lhe pedir que retornasse para evitar um esvaziamento do público. Eu estava presente no evento e notei o ocorrido, que me foi relatado dias depois por Emílio durante uma entrevista, exemplificando como alguns dançarinos se tornam referências em suas comunidades.

A noção de liderança indicada acima deve ser qualificada. Neste caso, o reconhecimento que leva a uma posição de liderança se deve ao desenvol- 
vimento de um tipo capital existencial, pois resulta da manipulação e domínio sobre um repertório de passos de dança, um patrimônio coletivo que recebe o nome de passinho.

O que caracteriza este repertório de passos? Em entrevista, DJ Marlboro afirmou que a dança sempre foi algo central no funk. O que é novo, de acordo com ele, é a atribuição de nomes, a classificação. Contudo, para os participantes desta pesquisa envolvidos com a cena da dança, algumas questões cronológicas marcam o desenvolvimento do passinho. Diversos dançarinos afirmam que até o começo dos anos 2000 a arte da dança entre homens não era algo muito comum. Desde os primórdios da cena funk, quando o estilo musical de preferência ainda era o R\&B (rhythm and blues americano), a dança black coreografada era uma prática muito comum entre homens (Vianna, I988; Essinger, 2005). Não é possível afirmar que o passinho inaugurou a dança masculina não-coreografada, mas certamente serviu, de acordo com relatos desde 2004, para estimular a prática.

O que mais marca o passinho é a sua apropriação característica de uma variedade bastante eclética de estilos de dança, como o break dance (muito associado ao hip-hop), o samba, o frevo e a capoeira, esta menos citada. Todos estes estilos surgem de uma base - que Cebolinha chamou de base do passinho -, que consiste num movimento em que uma das pernas se desloca de maneira angulada e rápida para frente e para trás da outra. Apesar desta mistura de estilos, o passinho se apresenta como uma prática dotada de unidade, ainda que contingente. Por exemplo, dançarinos discutem se determinados passos podem ou não ser incluídos em sequências de passinho, a inserção de estilos diversos nem sempre é aprovada, sendo muitas vezes motivo de críticas.

Em abril de 2013 me encontrei com Baianinho e Wanderson, que juntos formam a dupla de funk BW, do bairro do Jacaré. Muitas pessoas com as quais tive contato, incluindo outros dançarinos e produtores, já haviam me sugerido que entrasse em contato com Baianinho devido ao seu pioneirismo no passinho. Em entrevista, ele me disse que os duelos em bailes não existiam desde o começo do passinho, tendo começado em 2008.

Cebolinha, outro dançarino de passinho também reconhecido pelo seu pioneirismo, me disse que os duelos começaram quando dançarinos de comunidades diversas passaram a se encontrar em bailes pela cidade, promovendo uma rivalidade entre favelas, das quais os dançarinos se sentiam representantes. Após já ter conversado com Cebolinha sobre a noite do encontro no Jacaré, Baianinho me contou a versão dele dos fatos, que não diferiu muito da de Cebolinha:

Baianinho: Cebolinha foi no Jacaré, e eu era muito falado já, muito falado. Aí eu tava fazendo o show, que eram os Atraentes, e cheguei tarde no baile. Aí os moleques tinham mania de que quando chegasse alguém assim dançando, os moleques ficavam tudo no meu ouvido. 
Wanderson: Olha lá, vai deixar?

Baianinho: É tipo assim, eu sou do Jacaré, tem outro no Manguinho, outro do Complexo, outro na Rocinha, entendeu? Eu sou o melhor do Jacaré, aí o outro é o melhor dali, o outro daqui, o outro de lá. Mas se esse melhor veio na minha favela, eu sou o melhor, eu tenho o dever tipo de proteger. Tipo de continuar como melhor dali. Aí o Cebolinha veio na minha favela. Eu cheguei do show, aí veio geral unindo: Aí tem um moleque lá que está duelando com todo mundo. Aí eu, como? Cheguei na simplicidade. Ele tava até com a namorada dele, o Cebolinha. Aí comecei a dançar. Porque eu tenho um ditado na minha cabeça que eu tento passar para todo mundo que dança passinho. Que quem quer duelar não chama pro duelo, quem quer duelar sai entrando na roda e provoca.

As narrativas de Baianinho e Cebolinha sobre aquela noite revelam como a rivalidade entre diferentes áreas da cidade não impede a criação de laços afetivos entre dançarinos que superam fronteiras territoriais. A provocação e a competitividade são flagrantes. Leandra, uma influente dançarina na cena do passinho, me contou que o seu envolvimento com o estilo se deu por causa da falta de respeito que ela observou entre dançarinos em um fórum de Internet. Ela tomou para si a tarefa de mediar a comunidade existente no extinto Orkut, uma espécie de precursor do Facebook. Contudo, ela mesmo observou que, apesar da linguagem agressiva, os garotos ao se encontrarem fora da Internet não se agrediam fisicamente, preferindo deixar as disputas no âmbito da dança. Em 2013, quando conversei com Leandra, a comunidade do Orkut já se encontrava em declínio e havia sido substituída por uma página no Facebook. No entanto, de acordo com a dançarina, a participação nessa nova página não era tão ativa quanto na página original, chamada

"Passinho foda". A última edição da Batalha do Passinho ocorreu em 2013.

Baianinho, continuando sua narrativa sobre a noite do encontro com Cebolinha, disse:

Baianinho: Aí foi assim o duelo eu e o Cebolinha. Para ele deu empate, para muitos deram eu, para mim tanto faz, tanto fez. Mas foi o conhecimento, eu conheci ele, hoje em dia eu tenho ele como irmão, amo aquele moleque de coração.

Wanderson: E cada vez que tem um duelo você aprende mais um pouquinho.

Baianinho: É, pô. Como a gente vê quem ganhou o duelo? Não é o dançarino que vê. É a galera.

Wanderson: É a galera.

Baianinho Foi por isso que eu fui considerado o melhor do Rio. Entendeu?

Podemos perceber nos relatos acima que o tema do reconhecimento aparece de maneira destacada. No entanto, diferentemente da discussão de Watkins (20I0), restrita à questão do reconhecimento na relação professor/ aluno, temos no caso analisado dois eixos importantes: primeiramente, a relação entre dançarinos e seus iguais, outros dançarinos; em segundo lugar, a relação entre dançarinos e "outros", pessoas envolvidas ou não com o passinho, e que muitas vezes não conhecem tão bem as regras e convenções internas à dança, como produtores, jornalistas ou o público em geral. 
A relação entre dançarinos já foi considerada até aqui através do encontro entre Cebolinha e Baianinho. Entre dançarinos é observável uma mistura de carinho e amizade com agressividade e competitividade. Neste caso, o afeto aparece novamente como algo contraditório, difícil de ser explicado por meio de relações dicotômicas. O mesmo pode ser observado na relação entre dançarinos e não-dançarinos.

O afeto também se encontra presente, mas a disputa por liderança se torna fundamentalmente uma disputa por respeito e nela o problema da apropriação ganha relevo. Entre dançarinos existe, sim, a preocupação com a apropriação de estilos de um pelos outros, pois se entende que tal recurso - a imitação - prejudica a performance. Dançarinos seriam supostamente capazes de reconhecer a originalidade e o pioneirismo. Assim, aqueles externos ao passinho, por não saberem julgar bem a dança com base em seus critérios internos, acabariam contribuindo para a valorização desmerecida de dançarinos.

Curiosamente, Gambá, dançarino assassinado no final de 20 I e chamado por alguns de o "Rei do Passinho", aparece como um exemplo desta tendência. Segundo outros dançarinos, seu carisma seria maior do que suas habilidades, e teria permitido a ele conquistar a atenção e a predileção dos juízes na Batalha do Passinho de 2or I. Batalha do Passinho é uma marca registrada e refere-se a eventos em favelas cariocas onde dançarinos competem uns contra os outros por um prêmio em dinheiro e visibilidade. Diversas empresas patrocinam a Batalha do Passinho, como a Coca-Cola e a rádio FM O Dia. Em 2013 ocorreu a segunda edição da Batalha do Passinho, a primeira foi em 20II.

Meu objetivo não é discutir quem é o melhor dançarino de passinho, ou quem merece de fato reconhecimento ou não. A questão relevante é como dançarinos identificam os diversos caminhos para obter reconhecimento, tanto por dançarinos quanto por não-dançarinos. O dançarino precisa obter respeito e liderança entre seus pares. Contudo, com a visibilidade obtida pelo passinho na imprensa, ser reconhecido envolve também agradar a jornalistas, produtores e juízes em duelos agora institucionalizados.

\section{JULGANDO $O$ PASSINHO, JULGANDO O FUNK}

Os jovens dançarinos de passinho precisam agradar a não-dançarinos em duas esferas, dentro da dança e fora da dança. De acordo com dançarinos entrevistados, dentro da dança, uma performance mais teatral, marcada por "carisma" nas palavras de Leandra, parece agradar aos juízes.

Todos os dançarinos entrevistados revelaram certa ambiguidade em relação ao que pensam sobre duelos institucionalizados. Enquanto Baianinho frisou claramente que quem decide os vencedores em duelos dentro dos bai- 
les é a "galera", na Batalha do Passinho, por exemplo, três juízes decidem o vencedor. Alguns dos juízes foram classificados por um dos dançarinos como "pessoas muito importantes". Todos os dançarinos entrevistados fizeram ressalvas sobre a possibilidade de o passinho ser julgado por juízes que não conhecem profundamente o estilo. Outro dançarino chegou a dizer que tal tentativa configura um desrespeito à cultura deles.

Por outro lado, todos os dançarinos também concordaram em algum momento que a Batalha do Passinho serve para criar uma imagem positiva do passinho. Eles reconhecem que o estigma em relação à cultura funk ainda é forte e que estes eventos podem contribuir para reduzir este preconceito. Fora da dança os jovens são pressionados tanto por produtores quanto por seus pares a evitarem temas eróticos ou relacionados à criminalidade. Ao ser chamado para dirigir a segunda edição da Batalha do Passinho, que ocorreu em 2013, Dragaud descreveu para mim da seguinte forma o seu papel:

Então eu falei: "Beleza, eu vou dirigir". Aí eu comecei a conceber um cenário, eu coloquei um tipo de luz, mudei certas regras para tentar moralizar: não pode falar palavrão, não pode ter... falar putaria. Tem crianças vendo, então tem uma coisa que é uma classificação etária mesmo. Vamos criar certas regras para isso virar um espetáculo bacana, para a gente redimir o funk, que é um gênero que todo mundo gosta, mas que também sofre um preconceito enorme, e ele é a trilha sonora do passinho. Então eu comecei a dirigir. Tracei uma estratégia de mídia.

Na visão de Dragaud, o funk precisa ser redimido e o caminho mais claro parece ser dissociá-lo de temas como o erotismo e a violência. Alguns poderiam associar tal opinião com o fato de Dragaud ser um produtor ligado, por exemplo, à Rede Globo. Justificaríamos assim seus objetivos partindo de seu trabalho e posição social. Contudo, produtores como Zé Black e Reginaldo há muito tempo no ramo do funk, respectivamente das equipes de som Soul Grand Prix e CurtiSom, também acreditam que o proibidão "prejudica" o funk.

Já MC Leonardo, ainda que não seja exatamente a favor dos proibidões, defende o direito dos MCs cantarem sobre esse tema, mesmo reconhecendo que este estilo estigmatiza o funk. No entanto, de acordo com MC Leonardo, não podemos proibir que habitantes de favelas narrem seu cotidiano, como no caso da prisão de seis MCs acusados de incitação ao crime, apologia ao crime, associação com o tráfico de drogas e indução ao uso de drogas (Palombini, 2012). Neste caso, como existiu um processo legal, a apologia é definida e refere-se a uma conduta criminal. Contudo, apologia se tornou um termo utilizado também para definir a música funk. Como Palombini e Facina já observaram, o objeto da apologia não é necessariamente sempre explicitado, mas é "subentendido como o crime, o sexo ou ambos" (Facina \& Palombini, 2015: I8).

Durante entrevista com Wanderson e Baianinho tal ambiguidade aparece, mas como uma confusão que precisa ser corrigida. Ambos os entrevistados fazem questão de frisar que fazem "apologia ao sexo". À pergunta "o 
que é apologia", Wanderson responde: "O que é apologia? Vamos dizer, apologia ao sexo, porque quando fala apologia se pensa no crime. É música com sensualidade...". Wanderson e Baianinho buscaram claramente divorciar sua música do proibidão que narra o crime.

Tal discussão nos leva novamente à ideia de capital existencial. A própria narração, ainda que fictícia, da realidade vivida por habitantes de favela é estigmatizada e criminalizada, como no caso de seis MCs presos em 20I I por cantarem proibidões. Isso acontece apenas porque o funk pode ser ignorado como arte, tendo suas letras consideradas como confissões em forma de melodia e não como uma narrativa fictícia.

Uma vantagem do termo capital existencial é a possibilidade de se atenuar o tratamento da cultura ou da arte como um instrumento. Um exemplo é a ideia de que o funk serve o propósito de evitar que o jovem se envolva com atividades criminosas. Obviamente a arte ou a cultura podem ser - e frequentemente são - tratadas como um instrumento para atingir determinados fins; o próprio funk, por exemplo, já foi mobilizado neste sentido (Yúdice, 2003).

A cultura pode sim gerar efeitos indiretos. Contudo, considerando no Brasil as desigualdades relacionadas a área geográfica, cor da pele, origem social, acesso e conhecimento do sistema judiciário, não é surpreendente que certos indivíduos sejam mais facilmente criminalizados por determinadas condutas. Neste contexto, dificilmente podemos tomar como verdade absoluta que jovens moradores de favela precisem mais da cultura para não se tornarem criminosos do que jovens em outros locais da cidade.

Como já discutido, tal discurso apareceu frequentemente durante meu trabalho de campo. Pessoas ligadas ao funk afirmaram que o envolvimento com a música funk pode contribuir para que jovens não se envolvam com o crime. Outros utilizaram tal argumento voltando-se para uma discussão sobre representação: o jovem dançarino de passinho poderia fornecer uma nova face do jovem favelado. Não pretendo atacar diretamente estas visões, tampouco afirmar que o funk não possa contribuir para a vida desses jovens. Mas, acredito que a ânsia em defender o funk e justificá-lo como uma cultura que traz desdobramentos positivos é também uma das consequências do processo de criminalização da pobreza discutido por Facina (20ı). Assim, a defesa do funk também se encontra influenciada, de maneira indireta e não intencional, por pressupostos relacionados à criminalização da pobreza.

\section{E O AFETO?}

Haveria alternativas em termos de ação social para afirmar o funk como prática cultural para além da "conveniência da cultura" (Yúdice, 2003)? Quero argumentar que o passinho, assim como as Batalhas do Passinho, baseia-se no que chamarei aqui, inspirado por Leela Gandhi (2006), de comunidades 
afetivas. O mesmo poderia ser dito quanto ao movimento "Funk é cultura", que busca desde 2008 legitimar o funk como prática artística e cultural através da articulação de diversos agentes. Embora não possa me alongar a esse respeito, nas diversas vezes em que fui a protestos do movimento "Funk é cultura" pude observar pessoas de classes sociais, cor da pele e local de moradia distintos cantando: "eu só quero é ser feliz e andar tranquilamente na favela onde eu nasci", exemplificando a integração afetiva, ainda que talvez efêmera, entre grupos diversos através do movimento.

O termo comunidade afetiva busca dar conta de grupos que se articulam de uma maneira translocal, indicando que, embora a localidade seja um fator de importância, a interconexão delas também é relevante (Gandhi, 2006). Assim, comunidades afetivas não necessariamente se formam entre "iguais", ou seja, não são determinadas pelo pertencimento a uma dada classe social ou grupo étnico. Além disso, comunidades afetivas não se encontram confinadas dentro de fronteiras políticas, como seria o caso das chamadas comunidades imaginadas de Anderson (2008).

Em relação à atuação política, as comunidades afetivas permitem uma ação de base estética, ponto no qual podemos fazer uma crítica a Bourdieu. Para este último, conferir àqueles que vivem em condições "pouco humanas" a possibilidade de produzirem "cultura" ou "estética", lidas por Bourdieu a partir de uma perspectiva kantiana da arte pura, seria algo irresponsável:

O culto da "cultura popular" não passa, no mais das vezes, de uma inversão verbal e inconseqüente, portanto falsamente revolucionária, do racismo de classe que reduz as práticas populares à barbárie ou à vulgaridade. A exemplo do que sucede com certas comemorações da feminilidade que apenas reforçam ainda mais o domínio masculino, essa maneira um tanto confortável de respeitar o "povo"; contribuindo, sob a aparência de exaltá-lo, para encerrá-lo ou enfurná-lo no que ele é, ao converter a privação em escolha ou em realização eletiva, acaba proporcionando todas as benesses de uma ostentação de generosidade subversiva e paradoxal, deixando as coisas como estão, ou seja, uns com sua cultura (ou língua) realmente cultivada e capaz de absorver sua própria subversão elegante, outros com sua cultura ou língua destituídas de qualquer valor social ou sujeitas a brutais desvalorizações [...] (Bourdieu, 200I: 92).

Esta citação revela uma relação entre estrutura social e expressão artística na qual a última se encontra limitada pela primeira. Para chegar a tal conclusão, Bourdieu precisa apoiar-se em noções como autonomia desinteressada e arte pura. Curiosamente, a arte pura é criticamente desconstruída por Bourdieu e associada a valores burgueses, mas aparentemente tal valor seria tão impregnado que dificilmente poderíamos atribuir à arte popular o nome de "cultura" ou "estética". Além disso, ao negar ao "povo" a ideia de "estética" ou "cultura", considerando a importância de ambas na ação política, não restaria outra opção àqueles em condições desprivilegiadas que não a política do materialismo (Gandhi, 2006).

Vladimir Safatle, escrevendo para a Folha de S. Paulo, lamenta a produ- 
ção brasileira musical recente. De acordo com ele, o "centro da circulação [musical]" foi "completamente tomado por uma produção que louva a simplicidade formal, a estereotipia dos afetos, a segurança do já visto, isso quando não é pura louvação da inserção social conformada e conformista" (Safatle, 20I5). Neste trecho, o articulista se refere entre outros estilos ao funk. Em seguida, Safatle afirma, apoiando-se em Marx, que "os proletários" não possuem "música" e "cultura".

A principal contradição do texto citado acima é que, enquanto afirma que o funk, entre outros estilos, "não traz problema algum para o dominante", exemplifica paradoxalmente os "problemas" (no sentido de questionar padrões) trazidos pelo funk e representa uma reação (saudosista) de modelos que perderam espaço, como a canção. O próprio autor parece reconhecer isto ao intitular o seu texto "O fim da música".

Como afirmar que o funk não problematiza nada, que é apenas uma "inserção social conformada e conformista" (Safatle, 20I5), quando bailes funk são proibidos nas favelas cariocas até hoje, e até poucos anos atrás seus cantores eram colocados atrás das grades? Safatle lamenta o conformismo, enquanto revela um inegável conservadorismo. O termo differance pode nos ajudar novamente neste momento:

Analisar culturas de sobrevivência exige deslocamentos epistemológicos que permitam pensar a différance no sentido de Derrida: irredutível a consensos que silenciem conflitos. Negociação e tradução permanentes, hibridismos que desconstroem qualquer busca por pureza ou autenticidade, porque afirmam a performance como lugar da criação cultural. É preciso descolonizar o pensamento (Facina, Palombini \& Gomes, 2015: 3).

Neste artigo, Facina, Palombini e Gomes criticam Safatle por ignorar "o sentido antropológico da ideia de cultura" (Facina et al., 2015: 4). Deslocando aqui a discussão para o tema da estética, o que aconteceria caso abríssemos mão da noção de arte pura ou de autonomia desinteressada, ainda influente nos dias de hoje, para pensarmos em termos de uma autonomia interessada, como defende Leela Gandhi (2006)? Tal movimento representa também a forma de atuação das chamadas comunidades afetivas (Gandhi, 2006). A ideia "pós-hegeliana" (Gandhi, 2006: I6I) de autonomia interessada me parece extremamente fecunda, uma vez que possibilita o entendimento da prática artística e sua articulação com a prática política. Nas palavras de Gandhi, o conceito de autonomia interessada representa uma "liberação da monotonia prosaica de um imperialismo realista e narcisista, em direção aos numerosos e desconhecidos párias excluídos do mainstream" (Gandhi, 2006: I6I).

Embora no caso do movimento "Funk é cultura" a interação entre política e estética seja mais óbvia (Lopes, 20II), a entrevista com Rafael Dragaud revelou também motivações de cunho social para sua participação na Batalha do Passinho. Ele deixou clara sua intenção de ajudar os dançarinos, mesmo 
que lembremos aqui alguns dos problemas da apropriação do funk. Ainda que estimular a apropriação desta dança pelo mercado gere visibilidade e até renda, é o trabalho constante e duradouro de criação de comunidades afetivas que irá garantir que estes repertórios se estabeleçam como um patrimônio local e fonte de capital existencial.

Dançarinos também revelaram a importância do passinho para romper fronteiras sociais. O uso de palavras como amor e carinho apareceram durante o trabalho de campo com certa frequência. A virulência dos ataques verbais mútuos entre dançarinos também reforça a noção de que a intensidade do afeto é importante e que este não deve ser tratado por meio de oposições.

\section{CONCLUSÃO}

O que marca o passinho como uma manifestação única é exatamente o jogo entre a diferença e a semelhança, a differance. Não podemos definir o passinho partindo apenas da estrutura e da estabilidade de formas, ou seja, determinando quais passos podem ou não ser inseridos no passinho. O passinho é comunitária e continuamente construído através da performance da dança e das negociações entre dançarinos. É exatamente esta negociação constante que faz dele uma prática especialmente interessante para o estudo do capital existencial. A própria definição do que é passinho depende de comunidades afetivas que estabelecem as bases sobre as quais o passinho irá se desenvolver.

Para Bourdieu, pensar a "estética" ou a "cultura" a partir da perspectiva então dominante da estética desinteressada implica em não conferir tais rótulos à arte feita pelo "povo". Safatle propõe uma análise semelhante, como vimos. Contudo, de acordo com a crítica feita por Zangwill (2002), Bourdieu em diversos momentos utiliza estética e arte pura (ou estética pura) de maneira intercambiável. Procuramos atentar para a diferença entre esses termos ao mostrar indícios de que no funk articulações afetivas geram uma estética interessada, estranha à noção de arte pura.

A reflexão estimulada por uma apropriação crítica de Bourdieu, auxiliada pelas ideias de Leela Gandhi (2006) e Nettleton (2013), nos permite compreender por que o funk não pode ser descrito atualmente como estética desinteressada. Como pude observar, isto se deve, entre outros motivos, ao fato de se esperar dos MCs, dançarinos, DJs e produtores que justifiquem a utilidade da sua prática cultural.

Da mesma maneira que jovens parados pela polícia carioca dentro de ônibus em direção às praias da Zona Sul precisam provar que não irão cometer arrastões, no campo da cultura o ônus da prova também parece se inverter quando se trata de determinadas pessoas, normalmente negros, pobres e moradores de favela. De fato, como já dito, uma das maneiras mais fáceis 
de se conduzir o debate a favor do funk é enumerar seus possíveis benefícios sociais. No entanto, essa estratégia em si mina a possibilidade do funk ser visto também como arte e apenas como arte, sem a necessidade de justificativas adicionais. Além disso, deixa o funk à mercê do mercado, da imprensa e suas exigências.

Caso o funk não seja tratado pela perspectiva da economia criativa ou da redenção social, o que parece restar é o afeto tido como algo incontido e ameaçador. Um exemplo claro é a forma como o funk foi apresentado pela imprensa, principalmente durante os anos I990 (Herschmann, 2005; Lopes, 20II). Palavras como "pânico", "desesperança", "terror" foram utilizadas abundantemente em manchetes de jornal. Cabe notar, porém, que o tratamento pela imprensa não foi nem é homogêneo, pois a mesma imprensa que denigre o funk também abre espaços para a sua divulgação (Herschamann, 2005; Lopes, 20II).

Neste sentido, arrisco dizer que a instrumentalidade parece estar negativamente associada à possibilidade de reconhecimento de um capital existencial associado ao funk. Trata-se de uma hipótese a ser testada futuramente: quanto mais conveniente o funk se apresenta, mais reforça-se a noção de que ele precisa ser útil.

Um passo inicial nessa direção implica reconhecer a autonomia interessada do funk e sua associação com diversas comunidades afetivas, como quelas formadas por dançarinos de passinho. Utilizar o conceito de autonomia interessada não é o mesmo que falar no uso instrumental da cultura visando maior capital social, econômico ou cultural para indivíduos ou instituições. Descrevi aqui práticas culturais e artísticas gerando capital existencial para comunidades afetivas, algo que não irá se extinguir assim que um determinado produto cultural deixar de atrair a atenção da imprensa. O potencial para a criação de capital existencial através do uso instrumental da cultura é limitado por sua efemeridade. A conveniência do funk está sempre em risco de se esgotar uma vez que um de seus desdobramentos em voga perca visibilidade, em outras palavras, deixe de estar na moda.

O funk é, sim, uma "necessidade", como afirmou Bob Rum em sua canção Rap do Silva, afirmação retomada por Facina e Passos (20I5) ao analisarem a criação de um edital para o fornecimento de verbas para produções associadas ao funk. Contudo, esta "necessidade" emerge como uma forma de capital existencial mobilizado coletiva e afetivamente ("pra calar os gemido que existem nessa cidade"), e não apenas como "modismo" ou economia criativa. 
Bruno Barboza Muniz concluiu seu Ph.D em Sociologia pela London School of Economics and Political Science com a tese An affective and embodied push to Bourdieu's dispositional model: funk's cultural practices in Rio de Janeiro. Tal pesquisa resultou também no curta Funk is culture: music politics in Rio de Janeiro. Atua de maneira independente como produtor musical e de materiais audiovisuais. 


\section{NOTAS}

I Agradeço imensamente ao trabalho da equipe de Sociologia \& Antropologia e também aos pareceristas anônimos que contribuíram com importantes comentários ao texto inicialmente apresentado. Quero estender meus agradecimentos também à Coordenação de Aperfeiçoamento de Pessoal de Nível Superior (CAPES), sem a qual esta pesquisa não teria sido possível. Por fim, sou extremamente grato aos meus orientadores Mike Savage e Juan Pablo Pardo-Guerra da London School of Economics and Political Science, que me orientaram durante o período do meu doutorado, e também à professora Adriana Facina (Museu Nacional/PPGAS/UFRJ), que me ajudou com valiosos comentários durante a elaboração deste texto. Evidentemente, as opiniões expressas neste artigo são de minha inteira responsabilidade.

2 Criada em 2008 a APAFUNK realizou diversos protestos pela cidade, chamados de Rodas de Funk, visando chamar a atenção para a repressão aos bailes promovida pelas Unidades de Polícia Pacificadora. Um dos principais resultados alcançados pela instituição foi a aprovação de duas leis estaduais, 5543 e 5544, a primeira reconhecendo o funk como cultura e a segunda revogando outra lei anterior que dificultava a realização de bailes funk e festas rave.

3 Emílio Domingos dirigiu diversos filmes e vídeo clipes, entre eles "L.A.P.A." e "A batalha do passinho". Ele atua também como roteirista e produtor. A maior parte de seus filmes tratam de práticas culturais e temas relacionados à música, como o hip-hop ou o funk carioca.

\section{REFERÊNCIAS BIBLIOGRÁFICAS}

Anderson, B. (2008). Comunidades imaginadas: reflexões sobre a origem e difusão do nacionalismo. São Paulo: Companhia das Letras.

Bourdieu, Pierre. (2010). Distinction: a social critique of the judgement of taste. Londres: Routledge.

Bourdieu, Pierre. (200I) Meditações pascalianas. Rio de Janeiro: Bertrand.

Clough, Patricia. (2010). Political economy, biomedia, and bodies, In: Gregg, Melissa \& Seigworth, Gregory (orgs.). The affect theory reader. Londres: Duke University Press, p. 206-228. 
Derrida, Jacques. (1968). Differance. Disponível em: $<$ http://projectlamar.com/media/Derrida-Differance.pdf $>$. Acesso em 7 jan. 2016.

Facina, Adriana (20I4). Cultura como crime, cultura como direito: a luta contra a resolução or3 no Rio de Janeiro. Anais da 29a Reunião Brasileira de Antropologia, 3 a 6 de agosto, Natal/RN. Disponível em: <https://www.academia. edu/I I5958I4/Cultura_como_crime_cultura_como_ direito_a_luta_contra_a_resolu\%C3\%A7\%C3\%A30_oI3_no_ Rio_de_Janeiro>. Acesso em 5 abr. 2016.

Facina, Adriana. (2010). Cidade do funk: expressões da diáspora negra nas favelas Cariocas. Anais do VI ENECULT. Disponível em: <http://www.cult.ufba.br/wordpress / 24 340.pdf>. Acesso em 7 jan. 2016.

Facina, Adriana; Palombini, Carlos \& Gomes, Mariana. (20I5). A ferro e fogo: tiro, porrada e bomba. Disponível em: <https://www.academia.edu/I7071852/A_ferro_e_fo go_tiro_porrada_e_bomba>. Acesso em 6 jan. 2016.

Facina, Adriana \& Palombini, Carlos. (2015). O patrão e a padroeira: festas, criminalização e sobrevivências na Penha, Rio de Janeiro. Disponível em <https://www.academia. edu/I4II3652/_O_Patr\%C3\%A30_e_a_Padroeira_festas_populares_criminaliza\% $\mathrm{C}_{3} \% \mathrm{~A} 7 \% \mathrm{C}_{3} \% \mathrm{~A}_{3} \mathrm{O}$-e_sobre viv $\% \mathrm{C}_{3} \%$ AAncias_na_Penha_Rio_de_Janeiro_sexta_reda \%C3 \% A7 \% $3 \%$ A30>. Acesso em 6 Jan. 2016.

Facina, Adriana \& Passos, Pâmella. (20I5). "Baile Modelo": reflexões sobre práticas funkeiras em contexto de pacificação. Disponível em: <https://www.academia.edu/II89 222 I/_BAILE_MODELO_REFLEX\%C3\%95ES_SOBRE_ PR\% C3\%8ITICAS_FUNKEIRAS_EM_CONTEXTO_DE_ PACIFICA\% $3 \% 87 \% \mathrm{C}_{3} \% 83 \mathrm{O}>$. Acesso em 6 jan. 2016.

Ganem Misse, Daniel. (2014). Cinco anos de UPP: um breve balanço. DILEMAS: Revista de Estudos de Conflito e Controle Social, 7/3, p. 675-700.

Gandhi, Leela. (2006). Affective communities: anticolonial thought, fin-de siècle radicalism, and the politics of friendship. Durham: Duke University Press.

Herschmann, Micael. (2005). O funk e o hip-hop invadem a cena. Rio de Janeiro: Ed. UFRJ. 
Kushlev, Kostadin. (2015). Higher income is associated with less daily sadness but not more daily happiness. Social Psychological and Personality Science, 6/5, p. 483-489.

Latour, Bruno. (2005). Reassembling the social. Oxford: Oxford University Press.

Lopes, Adriana. (20I I). Funk-se quem quiser: no batidão negro da cidade carioca. Rio de Janeiro: Bom Texto/FAPERJ.

Massumi, Brian. (1995). The future birth of the affective fact. Conference Proceedings: Genealogies of Biopolitics. Disponível em: <http://www.brianmassumi.com/english/ essays.html>. Acesso em I4 jul. 2014.

Merleau-Ponty, Maurice. (2012). Phenomenology of perception. Londres: Routledge.

Nash, Jeniffer. (20II). "Home truths" on intersectionality. Yale Journal of Law and Feminism, 23/2, p. 445-470.

Nettleton, Sarah. (2013). Cementing relations within a sporting field: fell running in the English Lake District and the acquisition of existential capital'. Cultural Sociology, 7/2, p. I96-2Io

Palombini, Carlos. (20I2). O som à prova de balas. Disponível em: <http://www.proibidao.org/o-som-a-prova -de-bala/>. Acesso em 7 jan. 2016.

Perlman, Janice. (2010). Favela: four decades of living on the edge in Rio de Janeiro. Oxford: Oxford University Press.

Safatle, Vladimir. (2015). O fim da música. Disponível em: <http://www r.folha.uol.com.br/fsp/ilustrada/235828-o-fim-da-musica.shtml>. Acesso em 6 jan. 2016.

Skeggs, Beverly. (20I I) Imagining personhood differently: person value and autonomist working-class value practices. The Sociological Review, 59/3, p. 496-513.

Skeggs, Beverly. (2004). Class, self, culture. Londres: Routledge. Vianna, Hermano (I988). O mundo funk carioca. Rio de Janeiro: Zahar.

Watkins, Megan. (2010). Desiring recognition: accumulating affect. In: Gregg, Melissa \& Seigworth, Gregory (orgs.). The affect theory reader. Londres: Duke University Press, p. 269-288.

Zangwill, Nick. (2002). The concept of the aesthetic. European Journal of Philosophy, 6/I, p. 78-93. 


\section{Palavras-chave \\ Capital existencial; \\ Baile funk; \\ Passinho; \\ Afeto;}

Reconhecimento

Keywords

Existencial capital;

Baile funk;

Passinho;

Affect;

Recognition

\section{QUEM PRECISA DE CULTURA? O CAPITAL EXISTENCIAL DO FUNK E A CONVENIÊNCIA DA CULTURA}

\section{Resumo}

Qual é a conveniência do funk? Deve o funk ser útil para poder ser aceito como cultura? Muitas vezes discursos que buscam apresentar o funk como uma prática cultural legítima recorrem a sua suposta utilidade. Duas leituras se destacam. O funk serviria para retirar crianças e jovens do "mundo do crime" ou seria uma lucrativa forma de economia criativa. Este artigo desafia tais leituras sem, no entanto, negar a utilidade do funk. Contudo, não se trata apenas de instrumentalidade, mas de uma forma de gerar capital existencial mobilizada coletivamente e de maneira afetiva. Assim, além de contribuir para a criação de capital cultural, econômico e social, utilizado por indivíduos em suas lutas e competições dentro de campos específicos, o funk seria também mobilizado através de comunidades afetivas.

\section{WHO NEEDS CULTURE? FUNK'S EXISTENTIAL CAPITAL AND THE EXPEDIENCY OF CULTURE}

\section{Abstract}

How expedient is funk? Does funk need to be useful in order to be accepted as culture? Oftentimes, discourses that seek to present funk as a legitimate cultural practice mention its supposed usefulness. Two readings stand out. Funk serves to remove children and young people from the "world of crime" and it is also part of a lucrative creative economy. This article challenges these views without disregarding funk's usefulness. It argues that funk is not necessarily instrumental, but a way of generating existential capital deployed collectively and affectively. Therefore, besides contributing to the creation of cultural, economic and social capital used by individuals in their struggles and competitions within specific fields, funk is also mobilized through affective communities. 